\title{
Por una fundamentación de la dignidad de la persona. Una perspectiva desde la filosofía
}

\author{
On the basis for a foundation of the dignity of the person. \\ A Philosophical perspective. \\ DOI: https://doi.org/10.5377/koot.v0i11.10742 \\ URI: http://hdl.handle.net/11298/1197
}

Reynaldo Antonio Rivas Catedrático de Ética y Filosofía Universidad Tecnológica de El Salvador rivasreynaldo@gmail.com

\section{Resumen}

Fecha de aceptación: noviembre 2019

El presente artículo es una reflexión desde las categorías filosóficas sobre el concepto y contenido de la dignidad de la persona humana. Se pretende hacer una fundamentación teorética que dé razón de la excelencia substancial que le pertenece a la persona en cuanto persona. La razón de estas reflexiones tienen sentido, hoy más que nunca, de frente a una concepción generalizada de la cultura del descarte que preconiza lo desechable por encima de la dignidad absoluta, inviolable e insustituible de la persona, con las consecuencias que de ello se derivan.

Palabras clave: Antropología filosófica. Humanismo. Hombres - Aspectos sociales. Sociología.

\begin{abstract}
This article is a reflection on the concept and content of the dignity of the human person as viewed from different philosophical categories. It intends to make a theoretical foundation to explain the substantial excellence belonging to a person, as a person. The reason behind said reflections make sense today more than ever. This, in the face of a generalized conception of a culture that sees people as disposable items, as opposed to the absolute, inviolable and irreplaceable dignity a person, and its consequences therein.
\end{abstract}

Key words: Philosophical anthropology. Humanism. Men - Social aspects. Sociology. 


\section{A modo de introducción}

El tema de la Dignidad de la persona humana es un tópico siempre presente en las discusiones y, al mismo tiempo, factualmente olvidado en las decisiones. En pro de la dignidad, se apela a la reivindicación de grandes derechos, pero se olvida con facilidad el reconocimiento de los mismos a aquellos segmentos poblacionales más vulnerables y excluidos.

En el presente artículo se pretende dar razón, desde la filosofía, de las categorías que han forjado el concepto y contenido de la dignidad de la persona humana. Partimos de una perspectiva histórica desde el Humanismo Renacentista, que reclamó la centralidad del ser humano, de frente al Teocentrismo medieval. Sintetizamos la visión del materialismo propuesto por la izquierda hegeliana para, después, examinar el drama del humanismo propuesto por Nietzsche que va a impregnar no sólo el pensamiento, si no, sobre todo, la cultura moderna y posmoderna.

Habiendo dado cuenta de las aproximaciones histórico sistemáticas, intentaremos una definición tanto del concepto de persona como el de dignidad. Luego, a fin de ofrecer un esbozo del dualismo y del hilemorfismo, daremos una mirada sintética a la postura platónica y aristotélica-tomista sobre la fundación de la dignidad de la persona. En consecuencia, describiremos las notas características que brotan de la dignidad para, finalmente, ofrecer algunas consideraciones que creemos consecuentes del hecho fundamental de considerar a la persona con un valor de dignidad inalienable.

Es de notar que el presente no pretende ser exhaustivo. En efecto, responde sólo a algunas ideas de las corrientes filosóficas y deja fuera tantas otras (la fenomenología, la hermenéutica, el personalismo, por ejemplo). El criterio de elección responde a un interés personal por la filosofía clásica.

\section{Una mirada en contexto: del humanismo renacentista a la crisis del humanismo}

El giro antropocéntrico que marcó la llegada del Renacimiento, como período de transición entre la Edad Media y sus ideales de una Civilización Cristiana y la Edad Moderna con la exaltación de la razón y la promulgación de la verdad científica como único canon de verdad, que desplazaría las cosmovisiones geocéntrica y teocéntrica para dar paso al heliocentrismo y, más tarde, al tecnocentrismo, fue preconizado segun Pico della Mirandola (2010),

que da razón de un nuevo modo de concebir a la persona humana:

No te he dado, oh Adán, un lugar determinado, ni un aspecto propio, ni una prerrogativa específica, para que de acuerdo con tu deseo y opinión obtengas 
y conserves el lugar, el aspecto y las prerrogativas que prefieras. La limitada naturaleza de los astros se haya contenida dentro de las leyes prescritas por mí. Tú determinarás tu naturaleza sin verte constreñido por ninguna barrera, según tu arbitrio, a cuya potestad te he entregado. Te coloqué en el medio del mundo para que, desde allí, pudieses elegir mejor todo lo que hay en él. No te he hecho ni celestial ni terreno, ni mortal ni inmortal, para que, por ti mismo, como libre y soberano artífice, te plasmes y te esculpas de la forma que elijas. Podrás degenerar en aquellas cosas inferiores, que son irracionales; podrás, de acuerdo con tu voluntad, regenerarte en las cosas superiores, que son divinas. (p. 82).

Los altos ideales renacentistas pretendían poner al ser humano al centro de todo. En consecuencia, gracias a esa exaltación del mismo, esa época vio el florecimiento de un movimiento artístico, cultural, filosófico y científico que da cuenta de que algo ha cambiado en la concepción de la historia respecto al ser del hombre: no es más una simple creatura dejada a la suerte de la Providencia Divina ni al devenir del cosmos, sino que se convierte en dueño y señor, artífice de su propio destino.

Más tarde, con los postulados del racionalismo y, más aún, con los del idealismo, la exaltación de las capacidades humanas de tipo trascendente - especialmente la razón - alcanzarán sus límites y evidenciarán que no se puede llevar al ser humano al absolutismo idealista sin degradarlo. En consecuencia, la izquierda hegeliana zanjará la disyuntiva imponiendo una visión materialista que determinará la concepción de la persona cerrada a la trascendencia y encerrada en la inmanencia material. Para Hegel, la única realidad era el Espíritu Absoluto, que se realiza en la historia. La persona individual era algo irreal, cuya existencia tenía como fin realizar los proyectos del Absoluto. Karl Marx da un vuelco a este idealismo, sustituye el Espíritu con la Materia, y define la esencia del hombre como praxis. Si la materia es el principio absoluto, la esencia del hombre es la transformación de la materia por medio del trabajo. Queda, por tanto, el ser del hombre encerrado en unos postulados que miran sólo en la materialidad la realización y en la trascendencia una alienación de la cual debe emanciparse.

Esa idea emancipadora llevará a Nietzsche en La Gaya Ciencia a proclamar la muerte de Dios para que el hombre viva. Postulará las tres transformaciones que buscarán crear al superhombre, emancipado de todo valor, cultura, tradición; en último término, emancipado de Dios, de la trascendencia. Nietzsche pone en evidencia que, aquella idea de hombre que había transcurrido a lo largo de los siglos como una idea brillante en cuanto lo hacía pender de una fuerza mayor, se convierte en un yugo del cual hay que liberarse. El mismo Dios, en el cual el hombre había aprendido a reconocer el sello de su propia grandeza, comienza a 
parecerle como un antagonista, un enemigo de su dignidad. Por tanto, tiene que liberarse de Él para crecer como superhombre, siempre más alto.

Las sentencias nietzscheanas darán un vuelco al humanismo renacentista para fundar un humanismo dramático, sin apertura a la trascendencia; más aún, un humanismo que, como lo afirma el mismo Nietzsche al inicio de Ecce Homo, debe su carácter único a la fatalidad. Tal idea de fatalidad, recorrerá las filosofías existencialistas de tipo fatalista de J.P Sartre, como se evidencia en La Náusea o en su clásica obra El Ser y la Nada. El mismo Heidegger no escapa de ver en la muerte, la realización trágica e ineludible del sentido de la vida de la persona, cual proyecto tirado a la existencia para ser realizado. En consecuencia, el concepto de angustia será lo que mejor define la existencia y la vida misma de la persona.

Las visiones materialistas de tipo ateo de Nietzsche o del materialismo histórico cientificista de Marx, dieron como resultado unas consecuencias que podríamos juzgar como positivas, y otras como negativas. Por una parte, se propició el crecimiento de la técnica y de la ciencia, se avanzó con pasos agigantados en los grandes descubrimientos tecnológicos; la realidad objetiva en cuanto natural que había sido comprendida como universo creado se convierte ahora en objeto de estudio. El ser humano mismo es puesto en el tubo de ensayo y analizado en sus múltiples dimensiones, desde su corredor genético originario hasta las condiciones de posibilidad de mutación in vitro, que permiten nuevos escenarios no sólo para la reproducción de la especie humana manipulada, sino también para intentar la perpetuación de mejores condiciones de vida y de salud.

Pero, por otra parte, y en concomitancia al crecimiento científico, advertimos que el desarrollo tecnológico del cual los últimos decenios son testigos, no ha estado acompañado de un auténtico desarrollo humano. En consecuencia, junto a los grandes avances tecnológicos, nuestra época y la historia, da razón de una degradación humana y social que ha generado una cultura del descarte. Asistimos, pues, a lo que G. Vattimo denominó la crisis del humanismo y que Z. Bauman en su obra Vida Líquida no escatimó en describirla como una sociedad en la que nada puede declararse exento de la norma universal de la «desechabilidad» y nada puede permitirse perdurar más de lo debido.

En este nuevo escenario, el tema de la dignidad de la persona humana, ha pasado a ser un valor relativo, un discurso de conveniencia, un debate ideológico. Por tanto, a fin de ofrecer algunas consideraciones de tipo racional, trataremos de dilucidar, desde las categorías filosóficas, este tema, a sabiendas que la vastedad del mismo, supera la intención aquí pretendida. 


\section{Por una definición: persona y dignidad}

A lo largo de la historia se ha pretendido siempre categorizar y conceptualizar, a partir de la experiencia, a la persona y su dignidad. Tal pretensión es una tarea que comporta dificultades tanto de tipo ontológico como epistemológico. En efecto, ontológicamente hablando, la persona siempre es un misterio que escapa a categorías y conceptos finitos, limitados, pues no abarcan toda su amplitud y plenitud. Desde el punto de vista epistemológico, la dificultad radica en que, tal como lo manda la lógica formal, la definición no debe contener al definido, sino explicitarlo. En efecto, en la definición de persona y su dignidad, la persona es tanto el sujeto definitorio como también objeto de definición. Sin embargo, pese a estas dificultades, hemos de afirmar que, desde que el ser humano es autoconsciente, autoreflexivo, autorreferencial y ha pasado del mito al logos, ha buscado fundamentar la dimensión que lo trasciende en cuanto ser mundano, arrojado en la existencia y abierto a una trascendencia. Ha sido la búsqueda por la fundamentación de la dignidad de la persona humana que - en sus inicios reflexivos - intenta responder al porqué del valor de la persona. Por tanto, creemos que podemos acercarnos con los conceptos de la filosofía a una definición descriptiva del ser de la persona humana y su dignidad.

Probablemente, la mejor definición de persona de la filosofía clásica occidental es la que formuló Boecio (480-524 d.C), a quien la tradición conoce como el último de los romanos. En su Liber de persona, la define en los siguientes términos: "persona est rationalis naturae individua substantia» subsatancia individual de naturaleza racional). Si bien es cierto, esta definición puede parecer insuficiente, por prescindir de características fundamentales de la persona humana como la existencia, la relación, la corporalidad, la historicidad, la condición sexuada, la capacidad de amor, etc., gracias a su precisión lógica y a la exactitud de sus contenidos, la definición boeciana se hizo canónica y permaneció vigente durante siglos. El mismo Tomás de Aquino la retoma en el contexto de su definición de la Persona Divina. Los elementos, tanto en género como en diferencia específica que aporta esta definición, nos ayudan a comprender mejor el ser de la persona. En efecto, la persona es substancia en cuanto que permanece, subsiste en los cambios, tiene consistencia, es por sí y no en otro. Es decir, posee la densidad óntica propia de las substancias. Gracias a esta densidad óntica, se predica el término «persona» del ser humano en todas sus facetas: desde la concepción hasta su muerte. Por su parte, la individualidad refiere a la persona con el trascendental metafísico del unum que la hace única, determinada, distinta y diferente, no sólo de las otras especies, sino, también de sus semejantes. Finalmente, la diferencia específica por la cual la persona es persona, le viene dada de su naturaleza racional que la especifica dentro del amplio mundo de las substancias como 
un ser poseyente de inteligencia y voluntad; siendo estas las facultades que manifiestan la dimensión espiritual de la persona.

Habiendo establecido el concepto de persona, desde la filosofía clásica, toca ahora definir el concepto de dignidad. Para comprender a qué nos referimos cuando hablamos de dignidad, es preciso una aclaración terminológica. A menudo solemos hablar de «valor» y «dignidad» de la persona humana casi de modo indistinto. Sin embargo, sabemos que el término valor da lugar a diferentes interpretaciones, incluso aquellas de tipo mercantilistas donde valor tiene sentido sólo en cuanto condición de posibilidad de intercambio comercial o, subjetivamente hablando, valor refiere la apreciación subjetiva y, en muchos casos, relativa de las cosas. En cambio, cuando nos referimos a la persona, debemos hablar de dignidad, según la etimología latina de dignitas, cual forma abstracta del adjetivo dignos o decnus, que tiene la raíz sánscrita dec, al igual que el verbo decet y sus derivados decor, decus, decorare, que significan decoro, que es una cualidad superior, que refiere la excelencia. "Digno" es aquello por lo que algo destaca entre otros seres, en razón del valor que le es propio. Por tanto, la singular calidad o valía del ser personal reclama una estimación y una consideración tales que no permiten que la valía de la persona pueda ser comparada con nada, pues la dignidad excede lo evaluable. Esa prerrogativa del ser humano lo coloca aparte, infinitamente por encima de todo precio. De tal manera que no se puede colocar en una balanza ni hacerlo entrar en comparación, con no importa qué precio, sin atentar, de algún modo, a su sacralidad.

Entendemos pues, por dignidad de la persona humana, el presupuesto sine qua non la persona es entendida como tal; indica la excelencia de la persona, su ser en sí y su naturaleza misma que, en cuanto racional, se abre a la trascendencia (al mundo, al otro y a Dios). Tal presupuesto se refleja en la autonomía, incomunicabilidad del ser, unicidad e irrepetibilidad de la persona; pero, además, la dignidad también refiere el ser participado, la dimensión creatural por la que la persona participa del ser de su Creador según la medida de su esencia (el alma humana creada como única y distinta de la vida vegetativa y sensitiva; y, también distinta en cuanto intransferible entre iguales).

¿De dónde surge esa singularidad que confiere a la persona humana una dignidad tal que es inviolable? La filosofía - clásica especialmente - ha tratado de fundamentar una respuesta.

\section{Del dualismo platónico al hilemorfismo aristotélico-tomista}

Partimos aclarando que, la filosofía griega, no tuvo propiamente una noción de persona porque la noción fundamental que dirigió su pensamiento fue la de 


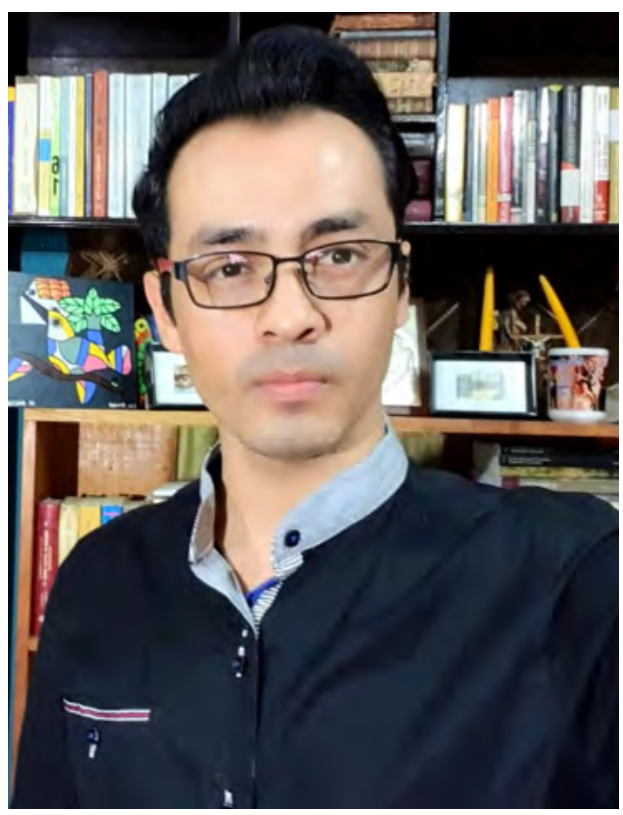

Reynaldo Antonio Rivas

naturaleza (physis). Tanto en la Grecia como en la Roma clásicas existía una indigencia significativa en su concepción de la persona: las personas eran sólo los ciudadanos libres, sujetos de plenos derechos y deberes (sui iuris esse), y se contraponía -negando que fueran personas- tanto a las mujeres, como a los esclavos y a los niños, que no poseían plenamente tales derechos. El concepto de persona como tal se lo debemos en gran manera al cristianismo. Sin embargo, tanto Platón como Aristóteles, tendrán como eje de reflexión - entre otros - el ser del hombre.

Platón hace pender la dignidad de la persona humana en cuanto que su alma participa del ser en el mundo inteligible, el mundo de las ideas, en el cual el alma es plena y vive en la contemplación de las ideas y que, por desgracia, se vio caída y encarcelada en el cuerpo. Esta visión platónica que, de algún modo va a asumir San Agustín, purificándola con la perspectiva teológica, va a fundar el dualismo que recorre la historia del cristianismo y que, en muchos casos, se ha convertido en una visión que rechaza la dignidad de la corporeidad y exalta la sola espiritualidad de la persona. Cuerpo y alma serían dos polos opuestos y en eterno litigio. En efecto, en el Mito del Mito del carro alado, que pertenece a uno de los Diálogos platónicos de la madurez, Platon (246 a-d), Platón compara el alma humana a un carro alado o fuerza en la cual van unidos una auriga y un par de caballos alados. El auriga conduce un carro 
tirado por una pareja de caballos, uno de los cuales es blanco, bello y bueno; el otro, negro, feo y malo. El caballo blanco (parte irascible), simboliza las tendencias positivas del hombre, las pasiones como el coraje o valor, la ira, la esperanza y está localizada en el pecho. El caballo negro (parte concupiscible), simboliza las tendencias negativas del hombre, los deseos más bajos, el instinto de conservación, la sexualidad y está localizado en el vientre. El Auriga (parte racional), simboliza la capacidad intelectual del hombre o pensamiento y está localizada en la cabeza.

El alma simbolizada en el carro alado, vive y se mueve en el mundo de las ideas; este es su sitio y su casa. Si el auriga controla la pareja de caballos, le será posible, gracias al poder de las alas, elevarse y gozar de la contemplación de las ideas. $\mathrm{Si}$, por el contrario, los caballos se le rebelan y no sabe elevarlos, una falta de dominio de la pareja de caballos hace perder el equilibrio y el alma, perdiendo también las alas, cae al mundo de las cosas. Ahí se acoge a algo sólido, donde se establece, y toma un cuerpo terrestre. Esta alma caída, sin alas y aprisionada en un cuerpo terrestre, se encuentra extraña y fuera de su elemento. El retorno del alma a su mundo original, requiere hacer nacer las alas para poder elevarse de nuevo y el amor o eros, es lo único que puede hace renacer las alas.

Ante esta visión del dualismo platónico, debemos afirmar que la dignidad de la persona humana nace de la completa comunión de los dos coprincipios que nos aporta la doctrina hilemórfica, iniciada por Aristóteles. Esta, establece que la sustancia es un compuesto de materia (el principio indeterminado) y forma (la esencia de la sustancia, que determina que sea lo que es). Esta teoría la aplicará Aristóteles a la antropología, sosteniendo que todo cuerpo está constituido por materia y forma, que componen un todo único. Así, el ser humano es un compuesto de alma con forma de cuerpo, cuya principal característica es la razón.

La teoría hilemórfica fue asumida, elevada y perfeccionada por Tomás de Aquino. En efecto, según el Aquinate, en la unión substancial de cuerpo y alma en la persona, no puede insertarse una dicotomía, ni paralelismo ni dualidad sin ir en detrimento de la unidad organizada y compleja del ser mismo de la persona humana, que goza de una riqueza estructural, un dinamismo funcional con mecanismos que exigen la coparticipación los dos principios (materia y forma) que le dan sentido al ser persona. La forma la constituye el alma racional y la materia el cuerpo humano.

Para Tomás de Aquino, la dignidad de la persona humana es inseparable de la noción de actus essendi participado. Todo cuanto existe, existe en tanto que ha recibido el ser por parte de Aquél que es el Ipsum Esse Subsistens. Los entes 
- la persona - participan del Esse divino. Y justamente porque se trata de participación, los entes no poseen el ser según toda su amplitud, sino que lo reciben según la medida que les es propia. La medida según la cual el ser es recibido por un ente es la esencia, también conocida como naturaleza.

Ya hemos mencionado más arriba que la naturaleza propia de la persona consiste en ser racional. Y, como dice Ugarte (2006) "el individuo o supuesto de naturaleza racional se llama persona para connotar la dignidad especialísima que le confiere la naturaleza racional, al permitirle poseerse a sí mismo por el conocimiento intelectual y el amor" (p. 74). Por tanto, a continuación, vamos a intentar una caracterización que se deriva del hecho de poseer tal naturaleza.

\section{Características de la persona que manifiestan su dignidad}

La dignidad de la persona humana se hace presente en unos rasgos característicos que evidencian la excelencia de su ser: la intimidad e interioridad, la libertad y la capacidad de apertura a la trascendencia, la perfección ontológica en el orden del ser y las distintas expresiones que nacen de las facultades específicas - la inteligencia y la voluntad -, entre otras, manifiestan la excelencia (dignitas) de la persona huma, su dignidad. Más específicamente, los actos que manifiestan la excelencia de la persona humana son los siguientes según Yepes Stork (2003).

- Experiencia de la libertad: La experiencia de ser origen y dueño de los propios actos comporta la experiencia íntima de la libertad: yo soy origen de mis actos, pero de tal manera que puedo originar un acto determinado o no originarlo, según mi voluntad.

- Autonomía operativa: la originalidad operativa, que le permite ser fuente de sus actos permite también que, normalmente, sea dueño de los mismos. Y esta capacidad de "dominio" sobre los propios actos, de ser "dueño de sí", de "poseerse", de "pertenecerse", es lo más relevante del ser persona.

- La intimidad: indica un dentro que sólo conoce uno mismo. De ahí que tener interioridad, un mundo interior abierto para mí y oculto para los demás, es intimidad, una apertura hacia adentro. La intimidad es el grado máximo de inmanencia de la persona. La intimidad tiene capacidad creativa. Por eso, la persona es una intimidad de la que brotan novedades.

- La corporalidad: es la manifestación de la intimidad de la persona. El cuerpo no se identifica con la intimidad de la persona, pero al mismo tiempo no es un añadido que se le pone al alma, como si fuera un apéndice: forma parte 
de nosotros mismos, yo soy también mi cuerpo. La máxima expresión del cuerpo es el rostro, que es una singular abreviatura de la realidad personal en su integridad.

- La intersubjetividad: somos seres constitutivamente dialogantes. No hay yo sin tú. El conocimiento de la propia identidad, la conciencia de uno mismo, sólo se alcanza mediante la intersubjetividad.

- El dar: la efusión, el salir de uno mismo, es lo más propio de la persona. Al ser sujetos dialogantes, siempre estamos en la reciprocidad del dar. (pp. 62-69)

\section{Algunas conclusiones consecuentes a la dignidad de la persona humana}

Tomás de Aquino "sostiene que el concepto persona significa lo que es perfectísimo en toda la naturaleza". Tal perfección es lo que concebimos como dignidad, que es una perfección intrínseca y constitutiva y le confiere a la persona un valor en sí misma y no puede ser instrumentalizada. Razón de esta sublime dignidad con el imperativo categórico nos la ofrece Kant (1996):

El ser humano y, en general, todo ser racional, existe como fin en sí mismo, no meramente como medio para uso caprichoso de esta o aquella voluntad, sino que debe ser considerado siempre al mismo tiempo como fin en todas las acciones, tanto las dirigidas hacia sí mismo como hacia otro ser racional $(. .$.$) .$

Los seres cuya existencia no depende de nuestra voluntad, sino de la naturaleza, tienen un valor relativo cuando se trata de seres irracionales, y por eso se llaman cosas; pero los seres racionales se denominan personas, porque su naturaleza ya los señala como fines en sí mismos, es decir, como algo que no puede ser usado como medio. (pp. 50-51).

Por tanto, debemos sostener que la dignidad de la persona es de valor absoluto. Esto quiere decir que es superior a cualquier otro valor que podamos encontrar en nuestro entorno, es un valor no intercambiable, manipulable o sustituible por nada. Por otra parte, la dignidad de la persona humana es el fundamento de los derechos humanos. En efecto, la Declaración Universal de los Derechos Humanos, firmada el 10 de diciembre de 1948, proclama en primer término: «todos los seres humanos nacen libres e iguales en dignidad y derechos, y dotados como están de razón y conciencia, deben comportarse fraternalmente los unos con los otros». Los derechos reconocidos a la persona en función de su dignidad, no son concesiones 
que el Estado hace, sino exigencias interiores que resultan del ser personal y que el Estado, si obra correctamente, no puede menos que reconocer.

Estas consideraciones tienen unas implicaciones que van más allá de un mero legalismo normativo. En efecto, considerada la persona en su dignidad, se le respeta en su integridad aun cuando hubiere características físicas que imposibilitaren reconocerlo en su ser y obrar. Esto implica el respeto por la vida en su dimensión unitaria e integral, implica reconocer a la persona como tal en las distintas facetas de su existencia, implica, además, el ejercicio y tutela de los derechos relativos a ella que nacen no del positivismo, sino de la naturalidad de la dignidad que no es algo convencional, sino connatural, intrínseco y consubstancial al ser persona.

\section{A modo de conclusión}

Este exiguo intento de reflexión, desde algunas categorías filosóficas, permite un acercamiento a este tema tan discutido y siempre inacabado. La dignidad de la persona es un presupuesto que no siempre ha sido suficientemente valorado ni evidenciado a lo largo de la historia. De hecho, la cultura grecorromana antigua da razón de una indigencia conceptual, pero, sobre todo, factual. Carecen no sólo de una auténtica definición de persona y su dignidad, sino que, además, abundan en justificar la segmentación social que reconoce a unos como personas y otros no.

Esa visión reductivista se impuso en el mundo occidental y se ha perpetuado como categorías de pensamiento $\mathrm{y}$, en consecuencia, como modus operandi en los sistemas económicos y políticos que han polarizado y segmentado la sociedad, dignificando a unos como habientes de valor y a otros como objeto de desecho de los cuales se puede prescindir con total facilidad y completa normalidad. Es el caso de los planteamientos en políticas de control demográfico o las políticas sanitarias que no reconocen como sujetos de derechos a aquellos que no son capaces de valerse por sí mismos o que -en la visión mercantilistaya no representan mano de obra en los mecanismos de producción.

Reconocer a la persona como digna, implica replantear las categorías de pensamiento que forjan los procesos de aquellos que toman decisiones y de la sociedad en general, de modo que la exclusión no sea más una práctica cotidiana y la persona sea reconocida como tal, independientemente de su condición social, raza, lengua o religión. Hoy más que nunca, el imperativo kantiano se vuelve más vigente y obligatorio: ¡la persona es un fin, nunca un medio! Por tanto, es un deber desterrar las concepciones utilitaristas, consecuencialistas, y 
proporcionalistas que fundan el juicio de valor únicamente en los criterios de utilidad y ganancia, amparados en una ética de los good business.

\section{Referencias bibliográficas}

Aquino de, T. (2001). Suma teológica. [versión de Adobe Acrobat Reader]. Recuperado de http://biblio3.url.edu.gt/Libros/s_tomas_aquil.pdf

Aquino de, T. (2012). Suma Teológica. Recuperado de https:/hjg.com.ar/sumat/ Aristóteles. (1995). Física I. Madrid. España: Biblioteca Clásica Gredos.

Bauman, Z. (2005). Vida líquida. Recuperado de https://books.google. com.sv/books/about/Vida_1\%C3\%ADquida.html?id=_3iTh3 snGAC\&printsec $=$ frontcover\&source $=$ kp_read_button\&redir_ $\mathrm{esc}=\mathrm{y} \# \mathrm{v}=$ onepage $\& \mathrm{q} \& \mathrm{f}=$ false

Burgos, J. M. (2005). Antropología: Una guía para la existencia. Madrid, España: Palabra.

Clavel, L. (s. f.). La belleza en el comentario tomista al de divinis nominibus. [versión de Adobe Acrobat Reader]. Recuperado de https://dadun.unav. edu/bitstream/10171/2198/1/02.\%20Luis\%20CLAVELL\%2C\%20 La\%20belleza\%20en\%20el\%20comentario\%20tomista $\% 20$ al $\% 20$ $\% \mathrm{C} 2 \% \mathrm{ABDe} \% 20$ divinis\%20nominibus $\% \mathrm{C} 2 \% \mathrm{BB}$.pdf

Hegel, G. W. F. (1966). Fenomenología del espíritu. México D. F., México: Fondo de Cultura Económica.

Heidegger, M. (2009). Ser y Tiempo. Madrid, España: Trotta.

Kant, I. (2007). Fundamentación de la metafísica de las costumbres. [versión de Adobe Acrobat Reader]. Recuperado de https://pmrb.net/books/ kantfund/fund_metaf_costumbres_vD.pdf

Lubac de, H. (1992). Il drama dell'umanesimo ateo. L'uomo davanti a Dio. Milán, Italia: Jaca Book.

Lucas Lucas, R. (2010). Horizonte vertical: Sentido y significado de la persona humana. Madrid, España: BAC.

Nietzsche, F. (1979). La Gaia Scienza. Milano, Italia: Mondadori.

Nietzsche, F. (2008). Ecce Homo. Madrid, España: Alianza Editorial.

Nietzsche, F. (2011). Así habló Zaratustra. Madrid, España: Alianza Editorial.

Pico della Mirandola, G. (2010). Discurso sobre la dignidad del hombre. Recuperado de https://historialimagen.files.wordpress.com/2009/08/ discurso-sobre-la-dignidad-del-hombre.pdf 
Platón. (2010). Platone, tutti gli scritti. (2010). Milan, Italia: Bompiani.

Reale, G. y Antiseri, D. (1988). Historia del pensamiento filosófico y científico. II del humanismo a Kant. Barcelona, España: Herder.

Sartre, J. P. (1976). L'être et le néant. essai d'ontologie phénoménologique. París, Francia: Gallimard French.

Sartre, J. P. (2012). La Náusea. Madrid, España: Alianza Editorial.

Ugarte, J. (2006). El derecho de la vida, el derecho a la vida bioética y derecho. Santiago, Chile: Jurídica de Chile.

Vattimo, G. (1990). El fin de la modernidad. Nihilismo y hermenéutica en la cultura posmoderna. Barcelona, España: Gedida.

Yepes Stork, R. (2003). Fundamentos de antropología. Un ideal de la excelencia humana. Navarra, España: EUNSA. 


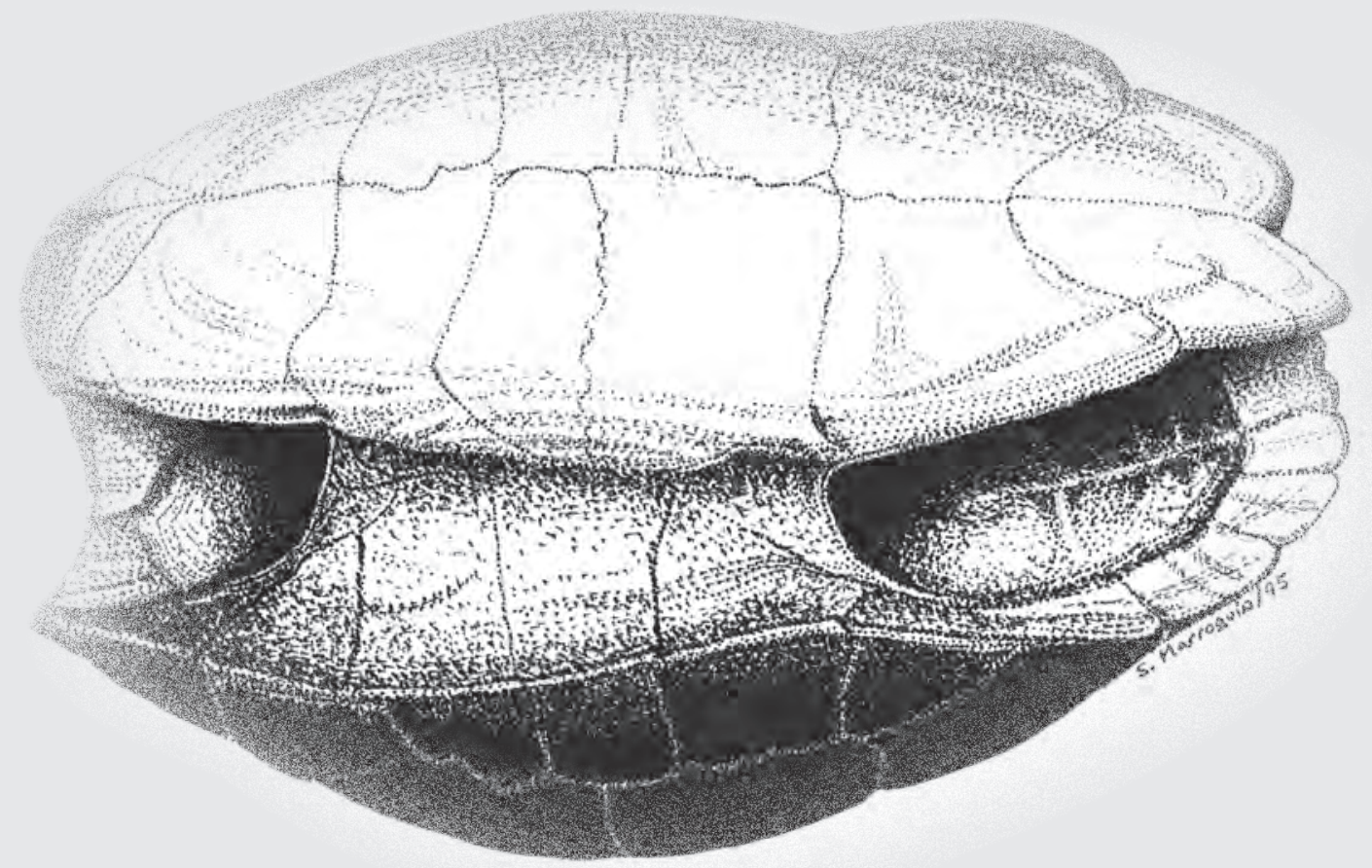

Carapacho de tortuga

Salvador Marroquín 